\title{
UN EJEMPLO DE REELABORACIÓN DE UN CUENTO DE ANIMALES EN DOS NOVELAS PICARESCAS (ALONSO, MOZO DE MUCHOS AMOS Y LAZARILLO DE MANZANARES)*
}

\author{
DANiEle ArCiELlo \\ Universidad de León \\ darc@unileon.es
}

\section{Consideraciones introductorias}

\begin{abstract}
$\mathrm{C}$ on tal de entender cabalmente la visión faunística que prevaleció durante varias décadas del siglo XVII, es forzoso aludir a la conexión ideológica con el simbolismo animal de la Edad Media, ya que nunca hubo un punto de inflexión tajante entre las dos épocas. Bastaría con un somero análisis para percibir cómo se reflejaba la idea del hombre y su relación con la naturaleza en la iconografía animalesca (Morales Muñiz, 1996: 230-231; Piñero Moral, 2013: 86-88). Exenta de todo tipo de estudio científico, la interpretación en este ámbito sufrió un proceso de fijación que estribaba en el contenido de antiguos textos religiosos o laicos. Cada símbolo seguía un esquema de criterios que establecía los puntos de la relación hombre/animal, en la que el dinamismo imprevisible y malicioso del ser humano se contraponía al estatismo de las alimañas, constituido por un conjunto de atributos que Morales Muñiz calificó de manifestaciones cósmicas (1996: 234-237). En el Siglo de Oro no tuvo lugar ningún hiato ideológico: «Predomina la visión simbólica, según la cual los animales tienden a ser considerados, en última instancia, como un mero espejo de los vicios y virtudes humanos» (Morgado García, 2011: 72), particularmente a principios del siglo.

Precisamente en esas fechas se publicó una obra que reprodujo fielmente los dogmas que aquel canon cultural imponía. En el Tesoro de la lengua castellana (1611) de Sebastián de Covarrubias Horozco, los animales se ajustaban a una voluntad moralizadora y aleccionadora, que justificó el empleo de fuentes clásicas, ignorando casi por completo las medievales (al margen de las versiones

* Mis agradecimientos van dirigidos a la profesora María Luzdivina Cuesta Torre, por haberme introducido en el maravilloso mundo de las fábulas y de los cuentos populares españoles.
\end{abstract}

Edad de Oro, XXXIX (2020), pp. 237-251, ISSN: 0212-0429 - ISSNe: 2605-3314

DOI: https://doi.org/10.15366/edadoro2020.39.013 
del Fisiólogo y de Alberto Magno). El autor se inspiraba en los únicos textos de su época que contenían una carga notable de valores representativos y moralizantes, entre los que sobresalían los Emblemas de Alciato (Morgado García, 2011: 78-79). Toda bestia en el texto mostraba un abanico de cualidades entre lo cristiano y lo pagano (si bien esto último subordinado a lo primero), asociado al bien o al mal, como en el caso de la raposa. En muchas ocasiones era expresión de crueldad y astucia malévola, pero en otras ejercía de maestra de sabiduría y prudencia. Por ejemplo, en la voz «romadizo» el autor corona su definición con una «fabulilla» popular:

Cuenta la fabulilla que, pidiendo el león a la zorra que se llegase a él y mirase si era verdad lo que los otros animales le decían, que le olía mal la boca, y viéndolos a todos despedazados, le respondió: «no huelo nada, que estoy romadizada». Advertencia para que a los señores no se les digan sus faltas, aunque ellos den licencia para ello y lo pidan. Esto no se entiende con los predicadores, ni con los confesores, ni abogados, porque estos tienen obligación a decirles verdad, aunque mueran por ello (Covarrubias Horozco, 2006: s.v.) ${ }^{1}$.

Se trata del cuento seleccionado para su análisis en el presente artículo, con el fin de cotejarlo con las versiones engastadas en dos obras de inspiración picaresca. El mismo relato ya figuraba en otro estudio, cuyo tema central versaba sobre los elementos fabulísticos más llamativos de reelaboraciones localizables en tres comedias barrocas (Arciello, 2015). Aquí, en cambio, se precisa examinarlo señalando los aspectos referidos al cuento folklórico, tal y como lo clasifican Camarena Laucirica y Chevalier, que lo titularon «El zorro rechaza hacer de árbitro», de tipo 51A. Este es el texto completo:

Una vez era un león y una leona que vivían juntos en una cueva. Y un día dijo el león a su compañera: - No quiero vivir más tiempo contigo, porque apestas. - ¿Cómo que apesto? Eso lo dices tú porque quieres irte a vivir con otra. Después de una gran disputa, determinaron celebrar una junta de animales, compuesta por un burro, un cerdo y una zorra, para que dijeran si la leona apestaba o no. Y cuando estuvieron todos reunidos acercóse el burro a la leona y después de olerla dijo estirando el hocico: - ¡Puf! Fiede que apesta. Entonces la leona le dio una bofetada que le tiró contra el suelo y le dijo: - ¿Cómo te atreves a ir en contra de tu reina? Después la olió el cerdo y para que no le sucediera lo mismo que al burro dijo: — ¡No!, no apesta. El león, al oír esto, le dio al cerdo: — ¡Toma! ¿Te atreves a contradecir lo que tu rey? Y le dio un puñetazo que le tendió al lado del burro. Se levantó la zorra de su asiento y, después de mirar compasivamente al burro y al cerdo, olió largo rato a la leona y separóse de ella diciendo: - Yo no huelo nada porque estoy constipada (1997: 96).

1 Su versión abreviada se puede leer en la voz «catarro» (Covarrubias Horozco, 2006: s.v.). 
Chevalier mencionó en un trabajo anterior el mismo relato, y confirmó su pertenencia al folklore oral (1983: 15 y 28). Su criterio de recopilación siguió el que adoptaron Aarne y Thompson, cuyas pautas dieron lugar a la edición de Uther (2011: 47). Este titula el tale type «The Fox Has the Sniffles», anteriormente denominado «Fox Refuses to be Mediator», motivo J811.2, y lo inserta en el apartado de la primera parte de «Wild Animals», cuyo elemento aglutinante es la astucia del zorro. También existía la versión con el lobo en lugar del león ${ }^{2}$.

Durante el Siglo de Oro, muchos cuentos y cuentecillos ${ }^{3}$ localizados en la producción áurea escrita eran en verdad cuentos orales que todo el mundo conocía, y que muchos autores recopilaban en refraneros o vocabularios, como en el caso de Correas y Covarrubias Horozco (Chevalier, 1975: 14-15)4. Tratándose de bienes mostrencos, se caracterizaban por estar sujetos a numerosísimas variaciones y solían traspasar las fronteras entre los diversos géneros (Molho, 1976: 22; Hernández Valcárcel, 2002: 32; Pedrosa, 2004: 125). Además, «los cuentos populares son combinaciones inestables de elementos, que tenían una existencia semiindependiente y que pasaban de uno a otros» (Burke, 1996: 197). En cuanto a sus versiones escritas, «en España, tampoco extrañaba que diversos ingenios literarios escribieran ficciones en que los animales desempeñaban papeles destacados y que se hallan a veces próximos a los cuentos y a las leyendas de animales» (Pedrosa, 2004: 126). A este respecto, la versión del relato ${ }^{5}$ que aparece en

2 Es interesante observar cierta afinidad con otro cuento, el 48* «Flatterer Rewarded, Honest One Punished», catalogado previamente como «The Bear who went to the Monkey for the Gold Chain», que incluye también el 68** (Uther, 2011: 43). Su semejanza permite inferir la posibilidad de intercambio entre ellos y la versatilidad que caracterizaba la prosa de los que aportaban modificaciones. Aun así, cabe señalar que dicho método de catalogación es susceptible de críticas, según lo planteado por Vladimir Propp. El lingüista ruso fundamentó su opinión inherente a la escuela finlandesa al desconfiar de una metodología que tiende a una segregación argumentativa excesiva, incompatible con la naturaleza compleja y heterogénea del tejido narrativo, típica del patrimonio folklórico (Propp, 1985: 18). Abenójar Sanjuán coincide con esta postura, consignando que «muchos de los descriptores que contiene The Types of International Folktales son muy concisos ya que han sido redactados teniendo en cuenta, fundamentalmente, las versiones europeas. Las descripciones de los tipos cuentísticos son, por tanto, insuficientes para abarcar el enorme espectro de variantes y de subgrupos de algunos cuentos distribuidos por varios continentes» (2018: 689).

3 Es posible hallar una distinción detallada entre cuento y cuentecillo en Chevalier (1978: 41-47).

4 El autor ratifica la supremacía de las fuentes orales frente a las escritas al examinar la elección por Alcalá Yáñez de un cuento de barberos para referirlo en Alonso, mozo de muchos amos (Chevalier, 1975: 161). Cita, además, las numerosas alusiones en las composiciones de la época; se trata de breves palabras que remiten a relatos apodícticamente muy conocidos, bien por los autores, bien por los lectores (1975: 33).

5 La escurridiza definición de cuento, fábula o relato atribuible a la producción aurisecular ha originado multitud de estudios filológicos, que muchos especialistas han publicado durante los dos últimos siglos. De los muchos, quiero mencionar a Zamora Calvo y su breve enumeración de denominaciones de «cuento» (2002: 551-553). Por ende, teniendo presente la oscilación semántica del término, nos decantamos por el uso indistinto de sinónimos a lo largo de nuestro estudio. 
el Catálogo de Camarena Laucirica y Chevalier fue recogida anteriormente por Aurelio del Llano Roza de Ampudia, que lo tituló «El león y la leona», n. ${ }^{\circ} 163$ (1993: 357) y que fue reproducido fielmente, sin ninguna diferencia, por los dos hispanistas 6 .

Hay aspectos de índole vulgar que alejan al relato de la cuentística culta y lo aproximan a lo popular. Entre todos, destacan la jocosidad y la intimidad del hogar, revelados por la pareja conyugal del león y la leona ${ }^{7}$. Por añadidura, Gonzalo Correas registra la sagaz respuesta final de la raposa: «No güelo nada, que tengo catarro. Excúsase uno que no sabe nada» (Correas, 2001: 568). El texto, a la postre, no procede «directamente de la tradición esópica, resultando una fusión entre El león viejo y la zorra y El león, el asno y la zorra» (Arciello, 2015: 186-187) ${ }^{8}$. Las resonancias folklóricas del cuento se hallan incluso en otro tipo presente en el catálogo elaborado por Uther, el ATU 1598 «Enmity of Lion and Man», en el que el mal aliento del león (o del oso) abre la senda para formular una serie de reflexiones sobre el peso de las palabras. Forma parte de la tradición de algunas regiones norteafricanas, de Europa Oriental y de España. Referimos aquí la descripción de dicho tipo, que en la edición que manejamos es 159B: «A lion (bear) helps a man with his work. The man praises his virtues but criticises "the bad smell of his mouth". The lion forces the man to strike him on his head with an axe. After a year, the man and the lion meet again. The lion says his wound is healed but it still hurts, and devours the man» (Uther, 2011: 112. El entrecomillado es nuestro).

En cambio, la versión ibérica, en el Catálogo de Camarena Laucirica y Chevalier, es fruto del examen de las versiones sefardíes, lo cual da lugar a un tipo folklórico similar, pero no idéntico, pese a que se siga indicando con 159B: «Después de una relación de amistad y mutua ayuda entre el león (o el oso) y el hombre, éste (o su esposa) "le falta al respeto de palabra". El animal le insta a causarles terribles heridas corporales. Al cabo del tiempo las heridas están curadas, no así el dolor» (1997: 296-297. El entrecomillado es nuestro). Es decir, aquello que origina la hostilidad no es la boca maloliente del león, sino que es algo más genérico que, de todas maneras, da el mismo resultado.

6 Sin embargo, en la edición que citamos falta la frase «Entonces la leona le dio una bofetada que le tiró contra el suelo y le dijo». Es probable que esto se deba a un error del editor, ya que se trata de un momento importante en el cuento y sí aparece en la recopilación de Camarena Laucirica y Chevalier, quienes reprodujeron el texto de la edición de 1925 (1997: 96).

7 En Arciello (2015: 186), se puede leer un sucinto análisis del cuento.

8 Asimismo, Donoso Rodríguez añade que «una versión alterada, con una mona en vez de una zorra y diferente final, aparece en Esta es la vida del Ysopet con sus fábulas historiadas (libro 3, fábula 20, f. 71 r.-v.)» (2005: 46). 
Abenójar Sanjuán, en un estudio muy riguroso, realiza un escrutinio de las variantes, ampliando el ámbito geográfico en el que estas se difundieron y apuntando a que también existieron versiones de algunas regiones en Argelia y de África central, además de una chipriota y de otra pomaca (Bulgaria) (2018: 690701). Resulta de gran interés que «pese a las discrepancias, a veces notorias, entre ellas, casi todas rematan con una invectiva contra aquellos que hablan mal de sus amigos» (Abenójar Sanjuán, 2018: 689). Muy sugerente es el relato incluido en los Castigos del rey don Sancho $\mathrm{IV}$, donde se utiliza una espada para herir al león (2018: 690). A lo mejor, la base de este cuento constituyó el armazón del asturiano «El león y la leona».

Retornando al siglo xvII, dos autores, Jerónimo de Alcalá Yáñez y Ribera y Juan Cortés de Tolosa, cuyas publicaciones convencionalmente se vinculan con el rótulo de picaresca, amoldaron la fabulilla, adecuándola a su voluntad, tanto en el estilo como en el contenido, como veremos más adelante ${ }^{9}$.

\section{La VERSión DEL CUENTO EN EL LAZARILLO DE MANZANARES (1620)}

De acuerdo con los posicionamientos críticos de numerosos expertos, el pícaro que Cortés de Tolosa retrata en su novela manifestaría desde el principio la ausencia de aquella sagacidad y sutileza crítica que el anónimo autor del Lazarillo de Tormes soslayadamente imbuyó en su personaje ${ }^{10}$. El Lázaro barroco se sitúa en una dimensión liminar entre la inocencia del Lázaro anterior y la mutación que

9 Conviene precisar que no fueron únicamente esos dos autores los que modularon el núcleo narrativo de dicha fábula. Francisco Santos, en su Periquillo el de las gallineras (1668), pronuncia por boca de su personaje una larga amonestación en contra de los jueces que inicuamente amparan a dignatarios criminales, cuyo colofón es el cuento de la zorra resfriada (2013: 156-157). Pero tanto el protagonista como la obra en sí difícilmente se pueden considerar adscritos a la producción truhanesca (Barrero Pérez, 1990: 29-30; Donoso Rodríguez, 2013: 17-21; Sevilla Arroyo, 2001: XLVIb-XLVIIb). Santos, en efecto, dio a luz un texto «difícil de encasillar; una novela cuyo protagonista debiera ser un pícaro pero que en realidad se opone diametralmente a esta figura» (Donoso Rodríguez, 2013: 47). De ahí la no inclusión de su análisis en este trabajo, ya que, en definitiva, prescinde de acepciones picarescas y al parecer, según anota Donoso Rodríguez en su edición de la novela (Santos, 2013: 157), tampoco demuestra mucha innovación, puesto que Alonso, mozo de muchos amos es la fuente directa de la fabulilla en cuestión.

10 En las páginas introductorias de la edición del texto hecha por Giuseppe Sansone, aparece un listado de estudiosos cuyo juicio restaba valor a la obra (1974: XII-XVII). El crítico italiano disentía en parte de tales aseveraciones, alegando en favor de su postura el mérito de Juan Cortés al presentar, según sus palabras, una suerte de «antilazarillo», que se alejaría del modelo primario. La originalidad del manuscrito se fundaría en un aspecto antitético a lo que fue uno de los leitmotiv del otro Lázaro. En efecto, si el hambre se convirtió en motivación propulsora de los frecuentes cambios de amos y consiguientes andanzas del pícaro salmantino, en el caso de su homónimo madrileño ocurría exactamente al revés. Este aprovechaba la oportunidad de saciarse sin muchos esfuerzos gracias a la generosidad de sus amos, lo cual determinaba su voluntad de 
padece por causa de las experiencias que va adquiriendo a lo largo de sus peripecias. Pero su recorrido no parece atenerse fielmente al cauce formativo del pícaro antonomástico; más que artífice de acciones criminosas, es espectador y testigo de las que cometen los personajes con los que se relaciona. Es una actitud evidente ya desde su primer oficio, el de mozo de una pareja de pasteleros; cuando decide acatar a la orden de buscar carroñas para rellenar pasteles, lo hace únicamente «por valer más, que ésse es el trato de los criados: dar gusto en todo a sus dueños» (Cortés de Tolosa, 1974: 27).

Contrariamente a su conducta servil, el mancebo que le acompaña en su ominosa tarea se reviste de cualidades truhanescas, al comer a escondidas y hurtando a su misma ama. El bribón, pues, es mucho más afín al personaje del manuscrito del siglo XVI — que se las ingenió de la misma forma para saciar su apetito, primero en detrimento del ciego y luego del sacristán avariento- que al mismo protagonista. De ahí que, a medida que se deja involucrar en asuntos criminosos, su anhelo de sufrir un escarmiento resulte incompatible con su comportamiento. A fin de cuentas, son sus amos o sus camaradas los que se dedican a perpetrar picardías; sus fechorías se deben a las perversidades de los demás, que le instigan a cometerlas. Cuando le hacen prisionero, efectivamente, es por algo ajeno a su inclinación al bien (Cortés de Tolosa, 1974: 119-120). Posiblemente su redención radique en el deseo de emanciparse de los demás, con objeto de evitar que influyan en sus decisiones futuras.

La reducción de invectivas y burlas a mera reproducción de los motivos satíricos de inspiración quevedesca ${ }^{11}$ coincide con una carencia de interés en el ataque a la sociedad de su tiempo. Esto lo confirmaría, por ejemplo, el episodio de su amo el canónigo, cuya intención de concertar matrimonio entre Lázaro y una viuda produce desconfianza en él. En un pasaje, pide a «Vuesa merced» que participe de la jovialidad que impregna aquello que va contando sobre este evento (Cortés de Tolosa, 1974: 133) y a lo largo de su biografía. La relación entre narrador y destinatario ficticio, ya que en otros lugares también se le invita a solidarizarse con el estado anímico de Lázaro, parece muy empática, de tinte amistoso ${ }^{12}$. Es como si Juan Cortés compusiera su obra para deleite del lector y no para formular

quedarse y no de huir. Por tanto, podemos suponer la invalidez de la teoría del simple remedo o continuación que se atribuye a la obra de Cortés de Tolosa (Sansone, 1974: XVII-XXI).

11 A este propósito, Miguel Zugasti presenta en su artículo una serie de textos críticos, cuyos autores corroboran la hipótesis de la influencia del genio de Quevedo en la escritura de Juan Cortés (1993: 1.018).

12 Idea compartida por Sansone (1974: XXIV) y Nieto Ibáñez (2004: 91-92), subrayando este último la personalidad mediocre de Lázaro a la hora de probar fortuna en el Nuevo Mundo. Se trata de un célebre tópico; el mismo Cervantes Saavedra abre la novela El celoso extremeño con una reflexión sobre el recriminable acto de huir hacia las colonias: «Refugio y amparo de los desesperados [...] engaño común de muchos y remedio particular de pocos» (2014: 109). 
alguna petición. Despojándose de la ironía punzante del otro Lázaro, la novela se reduce a un conjunto de bona mora, a las que es preciso atenerse, pero sin la eficacia del talento oratorio de Guzmán o la mordacidad de don Pablo. A la vista de lo comentado anteriormente, no es de extrañar que incluso el cuento fabulístico interpolado adquiera la función única de respaldar un gastadísimo cliché misógino, lo que avalaría ulteriormente la tesis, precedentemente mencionada, de una narración insípida y carente de espíritu creativo.

La primera parte del capítulo final de la novela consiste en un rosario de dicterios, que fungen de corolario a las interpretaciones oníricas del protagonista. Él es interpelado por una de las amigas del viudo - versadas en charlas insustanciales - con el fin de que le revele el significado de un sueño. Era habitual que muchos recurrieran a la ayuda de los que practicaban el arte de la oniromancia. $\mathrm{Su}$ actividad se valoraba considerablemente y suponía un modo eficaz de ganarse la vida. En efecto, no podemos ignorar «la dimensión personal que tuvieron los sueños en aquella época, regalando esperanzas, impartiendo consuelo y sirviendo como norte orientador en la vida de la gente» (Jordán Arroyo, 2017: 60). Pero en la novela de Cortés de Tolosa su papel social queda supeditado al evidenciar la bajeza del mundo femenino, acorde a las implicaciones éticas de la prosa del Siglo de Oro. Lázaro, pues, no deja escapar la oportunidad de insistir en el pecado como peculiaridad femenina (Cortés de Tolosa, 1974: 148-150).

Burlándose de la liviandad de la mujer, inevitablemente ocasiona la indignación de esta, a la que él contesta con un comentario que destaca la falta de gratitud de los que son incapaces de enfrentarse a la sinceridad, otra debilidad que se consideraba proverbialmente femenil. Para ello, Lázaro acentúa la amargura que implica la verdad, «compuesta siempre con çumo de axenxos» (Cortés de Tolosa, 1974: 148) frente a la dulzura de la mentira. El cuento popular que le viene a la memoria y que cierra dicha reflexión tópica presenta una variante ${ }^{13}$ con el perro que hace las veces del asno en el rol de víctima ingenua:

Acordéme entonces de la fábula del león, que, preguntando el mismo si tenía mal olor en la boca, matava a quien le dezía que sí. Experimentó este efecto el perro, pues de buenas a buenas le dixo que le olía muy mal. Ansí, señor perro, no haréys vos casas con azulejos: aprended de la zorra que dize que no huele porque está con romadizo (Cortés de Tolosa, 1974: 149-150).

13 Bien entendido que existen numerosos estudios relativos a los términos «variación» $\mathrm{y}$ «variante», el de Susana Chertudi se destaca por la lúcida diferenciación de las dos categorías; la variación indica cada elaboración de un cuento, mientras que la variante es el conjunto de elementos que reúnen varias versiones, y que a su vez adquiere su singularidad, al ser disímil de otras variantes (1967: 9). Por tanto, he decidido atenerme a este criterio para referirme a las prácticas creativas de los autores examinados.

Edad de Oro, XXXIX (2020), pp. 237-251, ISSN: 0212-0429 - ISSNe: 2605-3314 
Es muy sugerente que el autor se inclinase, en este caso, a fusionar dos géneros adscritos a la tradición oral: el cuento de animales y el refrán. El despropósito de edificar moradas con azulejos era máxima muy conocida ${ }^{14}$, y Cortés la emplea atinadamente indicando la torpeza de quien actúa impulsivamente, asociando el despilfarro de dinero con la insensatez del animal. Una chispa de originalidad se puede inferir de las connotaciones de necedad asignadas al perro: en esa época simbolizaba familiaridad y fidelidad, rasgos inequívocamente positivos de raigambre medieval (Covarrubias Horozco, 2006: s.v. «perro»; Morales Muñiz, 1996: 244). Tal vez Cortés haga referencia a una fuente más antigua, es decir, a la celebérrima fábula esópica del can mirando en el agua su figura reflejada (Esopo, 1978: 100-101). Tutear al perro, además, incrementa la intensidad de la reprehensión que veladamente se dirige hacia el lector y a la vez recalca la irracionalidad de las mujeres; el mensaje moral es fruto de la dicotomía comportamental perro/zorra. Al valerse de la «transformabilidad» de los cuentos populares orales (Molho, 1976: 17), folklore y paremiología colaboran en la creación de anécdotas que, en el caso del escritor madrileño, logran conferir mayor relevancia a una composición que difícilmente descollaría por otros recursos narrativos.

\section{ReELABORACIÓN Y AMPLIFICATIO DEL CUENTO:} ALONSO, MOZO DE MUCHOS AMOS (1624)

Las palabras de Camarena Laucirica puntualizan la exigüidad de cuentos de la tradición oral propiamente dicha, intercalados en las primeras novelas de pícaros; al parecer, las reminiscencias folklóricas pertenecen al ámbito culto y no a las capas sociales populares (1988: 82). Con todo, es palmario que la obra del doctor murciano $^{15}$, cuya primera parte se publicó en 1624, transgrede tal convención y se constituye como fuente literaria de la que brota multitud de cuentos y exempla de orígenes muy variados ${ }^{16}$. Su finalidad capital reside en apoyar argumentaciones de cariz moralizante que vertebran el diálogo entre el donado de un convento y su

14 En Correas: «No haremos casa con azulejos. Cuando se ve perder la hacienda» (2001: 570). Es equivalente de «No harás casa con sobrados, con dos ni tres altos» (2001: 570). En el Diccionario de autoridades se lee, en la voz «azulejo»: «Phrase común y familiar para dar à entender que el que disipa la hacienda no tendrá caudal para hacer obras, ni casas grandes: aludiendo à lo costosas que son las fábricas grandes, que es donde se suele poner este género de adorno. Lat. Non illi affulgebit fortuna, ut domum laterculis extruat tessellatis» (Real Academia Española, 1969: s.v.). Véase también La Dorotea: «iAy niña niña! No harás casa con azulejos. Ándate a amor por amor y a pelo por pelo, y al cabo al cabo, morir fea y nacer hermosa» (Vega y Carpio, 1958: 429).

15 He de aclarar que, pese a lo afirmado por el impresor de la primera edición, Jerónimo de Alcalá no era natural de Segovia, como certeramente anota Cea (1983: 7-8).

16 Cea apunta a que el lector puede toparse con hasta ciento veintisiete formulaciones digresivas y alrededor de doscientos refranes (1983: 62). 
vicario. El bello trasfondo que Alcalá Yáñez pincela desde los primeros capítulos alude, según Cea (1983: 57-58), al amor por la naturaleza que sentía san Juan de la Cruz, maestro durante un verano del médico murciano mientras realizaba sus estudios en un convento dominico. Asimismo, la estructura narrativa se aproxima notablemente a las homilías de dicha Orden, dado que sus miembros solían reforzar sus disertaciones por medio de una desbordante cantidad de anécdotas edificantes (Prieto de la Iglesia, 1979: 651).

Esencialmente Alonso, al igual que el Lazarillo de Cortés de Tolosa, se desliga de la propensión delictiva rufianesca, en aras de una elocuencia dogmática (Cea, 1983: 98), coadyuvada por «no haber sido jamás inclinado a cosas bajas y que desdicen de honrados términos» (Alcalá Yáñez y Ribera, 2005: 227). Es un personaje en el que se advierte cierta profundidad psicológica que le otorga mayor realismo; en algunos momentos de autoanálisis, hace hincapié en la petulancia e indiscreción que perfilan su formación juvenil ${ }^{17}$, y que sucesivamente cimentarán su apego a discursos de carácter sermonario. La entrega con la que pone en tela de juicio toda exhibición humana deplorable le induce a abordar temáticas conocidas, como la moral en el teatro. En efecto, el relato en cuestión se enmarca en la plática sobre el provecho que conllevaría la presencia de los comediantes en una nación ideal. Contrastando el texto con la cuentística popular, nos percatamos de la labor de extensión que Jerónimo de Alcalá lleva a cabo (2005: 448), conforme a aquello que Molho denomina «desfolklorización» de lo popular, en virtud de la pérdida de la función primigenia del cuento (1976: 43).

No obstante, el núcleo del mensaje, es decir, la prudencia frente a los poderosos, no se difumina en la ampliación del cuento. Más bien, con el auxilio de las preguntas del vicario que exhorta al donado a seguir narrando (una técnica sabiamente empleada a lo largo de toda la composición), la perplejidad misma que expresa el protagonista, al formular un juicio concluyente, introduce la fábula y la armoniza con el contexto. Y, desde luego, las alimañas mencionadas no pueden evitar una transmutación de corte antropomórfico, que en la versión recopilada por Llano Roza de Ampudias solo se esboza, y llega a cumplimiento con la pluma del novelista. El matrimonio de los dos leones se humaniza sentimental y jurídicamente. Se recurre a la figura neutral de un juez, oportunamente apelado por la leona para deshacer el lazo nupcial con su marido, harta de su despotismo y maldad, amén de su falta de amor por ella. El león, generalmente elogiado por

\footnotetext{
Valga de ejemplo cuando en el primer capítulo se evidencia su talento precoz «ya yo era mozuelo de quince a diez y seis, leía bien y escribía razonablemente; de la gramática era lo que sabía más que moderado, pudiéndome con justo título llamar Petrus in cunctis» (Alcalá Yáñez y Ribera, 2005: 231), y se intuye el rasgo medular de su futura interacción con los demás, es decir, la afición a entrometerse en todo evento que testimonie. En otro fragmento confiesa pecar de arrogante, por criticar constantemente las bribonadas de los estudiantes a los que sirve (Alcalá Yáñez y Ribera, 2005: 237).
} 
sus virtudes de realeza y coraje en la Edad Media (Morales Muñiz, 1996: 244), suele oscilar entre cualidades positivas y negativas. Covarrubias Horozco sostiene que «es animal ferocísimo, y juntamente generosísimo entre todos los animales después del hombre» (2006: s.v. «león»).

Empero, la magnanimidad no tiene cabida en el ánimo del león de Alcalá Yáñez, lo que se traduce en símbolo del poderío arrogante y tiránico, en el que se ve reflejada la idea de la inmutabilidad de las cosas. En un cuento narrado en el capítulo $\mathrm{V}$, enumera sus delitos en un afán de contrición, haciendo de árbitro la raposa (Alcalá Yáñez y Ribera, 2005: 334-337) ${ }^{18}$. Aun cuando da la impresión de redimirse, no puede eximirse de comenzar un «largo preámbulo de quién era, de su fortaleza, majestad y dominio que tenía sobre todas las bestias» (2005: 334). $\mathrm{Al}$ zorro no le queda otro remedio que absolverle y de paso granjearse su complacencia, para luego condenar a un asno culpable de un ínfimo delito. Es fácil de colegir, pues, que las dos anécdotas están ligadas entre sí, bien por la moraleja final bien por la actitud de los animales involucrados. Todo conduce a un ejercicio de escritura que, conforme a la estética barroca, consistía en «acoplar la fábula al ambiente de la época en la que se vive» (Martín García, 1996: 28). Sería arduo creer en una verdadera sátira que menoscabe a la soberanía monárquica en beneficio de los estamentos inferiores; es más admisible que los animales sean personajes aglutinados en la esfera de los clichés literario-culturales.

Apreciando la forma de actuar de los dos leones, nos cercioramos del recurso estilístico de la humanización y de cómo el conjunto de acciones convierte el cuento en un proceso civil en plena regla; el león solicita un plazo de tiempo para encontrar testigos fiables para su defensa, porque su pareja aduce razones adecuadas a su intención de divorciarse. El mal aliento del rey de los animales, elemento clave en el cuento popular, aquí resulta un subterfugio que la leona emplea para sus fines. La ampliación despierta la curiosidad del lector, que desea informarse de la resolución del pleito. Por lo tanto, Alcalá Yáñez, que aspira a transmitir el mensaje moralizador, les otorga mayor carga psicológica a las bestias implicadas, proporcionando indicios que hacen intuir el desenlace de la controversia. El león le asegura al lobo que su sincero juicio no tendrá consecuencias nefastas, y le quita la vida una vez escuchado el fallo negativo. El oso sufre el mismo destino -el novelista subraya que «le costó caro» (Alcalá Yáñez y Ribera, 2005: 448) decir la verdad-, conque el imperioso animal exige la opinión de la raposa, muy valorada por su inteligencia, y le insta a oler su boca. Pero ella evita pronunciar su opinión, justificándose con el constipado debido a las cazas nocturnas (Alcalá Yáñez y Ribera, 2005: 449).

18 Donoso Rodríguez asienta que «este extenso cuentecillo corresponde a una fábula, la n. ${ }^{\circ} 42(D e$ Presencia lupi, canis et asini), de una colección de Aviano, que le fuera agregada por un copista en el siglo XV» (Alcalá Yáñez y Ribera, 2005: 337). 
Las reflexiones que Alonso formula a modo de remate didáctico enfatizan una neutralidad que se prefiere a la arbitrariedad sin cimientos filosóficos - generadora de disparates y exclamaciones vanagloriosas-, más típica del vulgo ${ }^{19}$. La cordura de la raposa representa el arma ideal para encarar el cúmulo de situaciones caóticas que causa aquel «fluir constante, abundante, especialmente de la tradición del cuento familiar, donde destaca la sátira de estados, con todo su folclore relativo a "la vida de los casados"》 (Donoso Rodríguez, 2018: 105. El entrecomillado es nuestro). Además, la futilidad e incluso lo nocivo de entrometerse en contiendas de otros motivan otra digresión que matiza la terquedad de un personaje que, pese a su candidez, es incapaz de evitar su intervención en toda pendencia. El resultado de ello es el pago de multas exorbitantes y la detención, a pesar de su buena fe (Alcalá Yáñez y Ribera, 2005: 340-342). En general, se asiste a un procedimiento diegético que conjuga hábilmente discursos y apologías con relatos de tipo oral, tejiendo una urdimbre de géneros en boga durante aquellas décadas de florecimiento literario (diálogo, novela picaresca, cuento folklórico o excurso moralizante), y de forma simultánea comunica al lector el ambiente espiritual que envuelve a la obra. Los animales y su anfibológica naturaleza de probidad y desvergüenza se vinculan al esfuerzo de un médico que, junto con el velado deseo de un reconocimiento literario que no obtuvo con su obra anterior — Los milagros de Nuestra Señora de la Fuencisla (1615) — ${ }^{20}$, ansía inculcar fundamentos de vida honrada, valiéndose de un donado y de su locuacidad en la amenidad de jardines monacales.

\section{A MODO DE CONCLUSIÓN}

En esta breve investigación, que ha resumido algunos de los matices escriturales de dos autores auriseculares, se ha ilustrado la manera de configurar un producto procedente de la matriz cuentística verbal y la realización de cambios contundentes con respecto a las fuentes originarias. De importancia primordial ha sido patentizar la idiosincrasia de figuras que, manteniendo pleno respeto por las convenciones prosísticas de la época, se caracterizan por seguir con miramiento un código ético que intensifica el didactismo imbuido en las aventuras de Lazarillo y Alonso. Acercándose al paradigma picaresco, Cortés de Tolosa y Alcalá Yáñez forman parte de un grupo de escritores que «lo renuevan, en coalescencia con su contexto

19 Aspecto reiteradamente marcado por Alcalá Yáñez y Ribera ya a partir del prólogo, en el que el narrador se enfrenta a las reprimendas implacables del irónicamente apellidado «piadoso lector» (2005: 220). Pocas líneas después, si bien no es estilísticamente innovadora, la sugestiva analogía con las tribulaciones que padece un navío a merced de vientos inclementes ilustra eficazmente la angustia de los que se someten a los dictámenes de un público desconsiderado.

Un disgusto que Cea corrobora en su ensayo (1983: 53-54). 
inmediato y según el genio de cada autor, tanto en la forma como en el fondo» (Muñoz Sánchez, 2014: 453), mediante el manejo de artificios literarios propios. En este trabajo hemos visto cómo con perspicacia intervienen en la remodelación de un cuento oral que, al derivar en el universo de la palabra escrita, queda subyugado a exigencias estructurales de tipología distinta. De todas ellas, prima sin duda, en palabras de Soons al referirse a la fabliella o cuento risible, «una masiva amplificatio, que le da las dimensiones de una novela convencional» (1976: 9).

No sería arriesgado afirmar que la propia dilatación diegética sea una prueba concluyente de un acto de plasmación que consagra la vinculación entre lo hablado y lo leído. Alcalá Yañéz y Ribera y, en menor medida, Juan Cortés de Tolosa, a través del cultivo de la prosa extensa, hacen que perviva aquella conmistión que configuraba la literatura desde la Edad Media. Enseñanza moral y deleite, preceptos de eruditos y chanzas de vulgo se fusionan en una amalgama armónica de avisos y anécdotas jocosas. Y aunque vaya menguando a lo largo del siglo XVII la dedicación a la recopilación de dichos, apotegmas o refranes populares, de forma extraoficial siguen sobreviviendo en las obras de la estética narrativa más en boga, es decir, la picaresca.

\section{BiBLIOGRAFÍA}

AbeNóJAR SANJuÁn, Óscar (2018). «La enemistad entre el león y el hombre (ATU 159B): de un apólogo medieval a la tradición oral bereber». eHumanista: Journal of Iberian Studies, 38, pp. 689-703. DOI: https://bit.ly/2OvpN1M.

Alcalá YáÑez y Ribera, Jerónimo de (2005). Alonso, mozo de muchos amos (primera y segunda parte). Miguel Donoso Rodríguez (ed.). Madrid / Frankfurt am Main: Iberoamericana / Vervuert.

ArCiello, Daniele (2015). «La sabiduría de la raposa y su actitud frente a los poderosos: la fábula del 'León y la leona' en varias obras teatrales del Siglo de Oro». Lectura y Signo, 10, pp. 185-195. DOI: https://bit.ly/2YscjIY.

Barrero Pérez, Óscar (1990). «La decadencia de la novela en el siglo XVII: el ejemplo de Francisco Santos». Anuario de Estudios Filológicos, 13, pp. 27-38.

BurKe, Peter (1996). La cultura popular en la Europa moderna. Antonio Feros (trad.). Madrid: Alianza Editorial.

Camarena Laucirica, Julio (1988). «El cuento de tradición oral y la novela picaresca». Revista de Dialectología y Tradiciones Populares, 43, pp. 67-82.

Camarena Laucirica, Julio y Maxime Chevalier (1997). Catálogo tipológico del cuento folklórico español. Cuentos de animales. Madrid: Gredos.

CEA, Fidel (1983). Los milagros de Nuestra Señora de la Fuencisla y El donado hablador de Alcalá Yáñez y Ribera en la evolución del género picaresco. Segovia: Diputación Provincial.

Cervantes SaAvedra, Miguel de (2014). Novelas ejemplares II. Henry Sieber (ed.). Madrid: Cátedra. 
Chertudi, Susana (1967). El cuento folklórico. Buenos Aires: Centro Editor de América Latina.

Chevalier, Maxime (ed.) (1975). Cuentecillos tradicionales en la España del Siglo de Oro. Madrid: Gredos.

CheVAlIER, Maxime (1976). Lectura y lectores en la España de los siglos XVI y XVII. Madrid: Turner.

Chevalier, Maxime (1978). Folklore y literatura: el cuento oral en el Siglo de Oro. Barcelona: Crítica.

Chevalier, Maxime (ed.) (1983). Cuentos folklóricos españoles del Siglo de Oro. Barcelona: Crítica.

CORreas, Gonzalo (2001). Vocabulario de refranes y frases proverbiales. Louis Combet (ed.). Madrid: Castalia.

CORTÉs DE TOLOSA, Juan (1974). Lazarillo de Manzanares con otras cinco novelas. Giuseppe E. Sansone (ed.). Madrid: Espasa-Calpe.

Covarrubias Horozco, Sebastián de (2006). Tesoro de la lengua castellana o española. Ignacio Arellano y Rafael Zafra (eds). Madrid / Frankfurt am Main: Iberoamericana / Vervuert.

Donoso Rodríguez, Miguel (2005). «Estudio preliminar». En Jerónimo de Alcalá Yáñez y Ribera, Alonso, mozo de muchos amos. Miguel Donoso Rodríguez (ed.). Madrid / Frankfurt am Main: Iberoamericana / Vervuert, pp. 13-157.

Donoso Rodríguez, Miguel (2013). «Estudio preliminar». En Francisco Santos, Periquillo el de las gallineras. Miguel Donoso Rodríguez (ed.). New York: IDEA, pp. 13-71.

Donoso Rodríguez, Miguel (2018). «Nuevos antecedentes sobre los cuentecillos de Alonso, mozo de muchos amos (1624-1626), de Jerónimo de Alcalá Yáñez». Hipogrifo: Revista de Literatura y Cultura del Siglo de Oro, 6, 1, pp. 103-116.

Esopo (1978). Fábulas de Esopo. Vida de Esopo. Fábulas de Babrio. Carlos García Gual (ed.). Madrid: Gredos.

Hernández Valcárcel, María del Carmen (2002). El cuento español en los siglos de oro. Siglo XVII. Murcia: Universidad de Murcia.

Jordán Arroyo, María V. (2017). Entre la vigilia y el sueño. Soñar en el Siglo de Oro. Madrid / Frankfurt am Main: Iberoamericana / Vervuert.

Llano Roza de AmPudia, Aurelio del (1993). Cuentos asturianos recogidos de la tradición oral. Oviedo: Grupo Editorial Asturiano.

Martín García, Francisco (1996). Antología de fábulas esópicas en los autores castellanos (hasta el siglo XVIII). Cuenca: Universidad de Castilla-La Mancha.

Molno, Mauricio (1976). Cervantes: raíces folklóricas. Madrid: Gredos.

Morales MuÑIz, María Dolores Carmen (1996). «El simbolismo animal en la cultura medieval». Espacio, tiempo y forma, Serie III, Historia Medieval, 9, pp. 229-256.

Morgado García, Arturo (2011). «La visión del mundo animal en la España del siglo XVII: El Bestiario de Covarrubias». Cuadernos de Historia Moderna, 36, pp. 67-88.

MuÑoz SÁNCHEZ, Juan Ramón (2014). «La Corte, del mundo maravilla: la picaresca durante el reinado de Fernando IV». Nueva Revista de Filología Hispánica, 62, 2, pp. 383-480.

NiETo IBÁÑEz, Jesús María (2002). La novela en la literatura española: estudios sobre mitología y tradición clásicas (siglos XIII-XVII). León: Universidad de León. 
Pedrosa, Juan Manuel (2004). Los cuentos populares en los Siglos de Oro. Madrid: Ediciones del Laberinto.

PIÑERo Moral, Ricardo (2013). «De fábulas y bestiarios: la estética de los animales en la Edad Media». Estudios Humanísticos. Filología, 35, pp. 85-96.

Prieto DE la Iglesia, María Remedios (1979). «Picaresca, ascética y miscelánea en el Dr. Alcalá Yáñez». En Manuel Criado de Val (coord.), La picaresca: orígenes, textos y estructura. Actas del I Congreso Internacional sobre la Picaresca. Madrid: Fundación Universitaria Española, pp. 647-666.

Propp, Vladimir Iakovlevich (1985). Morfología del cuento. F. Díez del Corral (ed. y trad.). Madrid: Akal.

Real Academia Española (1969). Diccionario de autoridades. Madrid: Espasa-Calpe.

SAnsone, Giuseppe E. (1974). «Introducción». En Juan Cortés de Tolosa, Lazarillo de Manzanares con otras cinco novelas. Giuseppe E. Sansone (ed.). Madrid: Espasa-Calpe, pp. VII-XLI.

SAntos, Francisco (2013). Periquillo el de las gallineras. Miguel Donoso Rodríguez (ed.). New York: IDEA.

Sevilla Arroyo, Florencio (2001). «Presentación». En Florencio Sevilla Arroyo (ed.), La novela picaresca española. Toda la novela picaresca en un volumen. Madrid: Castalia, pp. V-LIII.

Soons, Alan C. (1976). Haz y envés del cuento risible en el siglo de oro: estudio y antología. London: Tamesis Books.

UtHer, Hans-Jörg (2011). The Types of International Folktales. A Classification and Bibliography. Based on the System of Antti Aarne and Stith Thompson. Part I: Animales Tales, Tales of Magic, Religious Tales, and Realistic Tales, with an Introduction. Helsinki: Suomalainen Tiedeakatemia.

Vega y Carpio, Félix Lope de (1958). La Dorotea. Edwin S. Morby (ed.). València: Castalia.

Zamora CALvo, María Jesús (2002-2003). «El cuento, desde su origen hasta su inserción en tratados de magia». Archivum, 52-53, pp. 551-565.

Zugasti, Miguel (1993). «La sátira antifeminista en la narrativa de Juan Cortés de Tolosa. La adaptación de un tópico». En Manuel García Martín (coord.), Estado actual de los estudios sobre el Siglo de Oro: actas del II Congreso Internacional de Hispanistas del Siglo de Oro. Salamanca: Universidad de Salamanca, pp. 1.017-1.025.

Recibido: 06/01/2019

Aceptado: 03/04/2019 


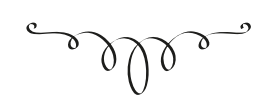

UN EJEMPLO DE REELABORACIÓN DE UN CUENTO DE ANIMALES EN DOS NOVELAS PICARESCAS (ALONSO, MOZO DE MUCHOS AMOS Y LAZARILLO DE MANZANARES)

RESUMEN: Característica clave de la literatura áurea fue el indisoluble vínculo entre tradición oral y producción escrita; estos dos elementos dieron lugar a aquello que hoy consideramos como una de las épocas de mayor florecimiento cultural de la península. Teniendo en cuenta dichas consideraciones, el presente artículo propone observar cómo un cuento folklórico de animales se reelabora en dos obras adscritas al género picaresco. Tras un repaso de los aspectos medulares de los protagonistas de las novelas en cuestión, se pondrán de relieve las aportaciones personales de cada uno de los autores analizados a la hora de moldear el cuento, subyugándolo a sus pretensiones ético-literarias.

PALABRAS CLAVE: cuentos de animales, folklore, picaresca, siglo XVII.

AN EXAMPLE OF RE-ELABORATED VERSION OF AN ANIMAL TALE

IN TWO PICARESQUE NOVELS (ALONSO, MOZO DE MUCHOS AMOS AND LAZARILLO DE MANZANARES)

ABSTRACT: The key characteristic of Seventeenth century literature was the binding connection between oral tradition and written production. The two elements gave birth to what is currently considered as one of the most significant cultural prosperity age for Spain. Taking into account these considerations, the present article proposes to analyse the re-elaboration of a folkloric animal tale in two works attributed to the picaresque genre. After a review of the central aspects of protagonists' personality in the novels in question, it will be highlighted each author's personal contributions, as a result of the remodelling of the tale, subjugated to their ethic-literary intentions.

KeY wORDs: Animal Tales, Folklore, Picaresque Literature, Seventeenth-Century. 